\title{
Creation of a Remote Sensing Portal for Practical Use Dedicated to Local Goverments in Kyushu, Japan
}

\author{
Kohei Arai ${ }^{1}$ \\ ${ }^{1}$ Graduate School of Science and Engineering \\ Saga University \\ Saga City, Japan
}

\author{
Masaya Nakashima ${ }^{1}$ \\ ${ }^{1}$ Department of Information Science \\ Saga University \\ Saga City, Japan
}

\begin{abstract}
Remote sensing portal site for practical uses which is dedicated to local governments is created. Key components of the site are (1) links to data providers, (2) links to the data analysis software tools, (3) examples of actual uses of the satellite remote sensing data in particular for local governments. Users' demands for remote sensing satellite data are investigated for the local governments situated in Kyushu, Japan. According to the users' demands, the remote sensing portal site is created with the aforementioned key components. For the examples of remote sensing data applications, creation of land use maps, disaster mitigations, forest maps, vegetation index map for evaluation of vitality of agricultural fields and forests, etc. are taken into account. In particular for forest map creation, it is created with free open source software: FOSS of classifiers together with open data API derived training samples applied to Landsat-8 OLI data. On the other hand, volcanic eruption is featured for disaster relief with $3 \mathrm{D}$ representation by using open data derived DEM data. In accordance with the users' evaluation reports, it is found that the proposed portal site is useful.
\end{abstract}

Keywords-Remote Sensing; Satellite data; Land use map creation; Disaster prevention; Normalized Difference Vegetation Index: NDVI; Forest map; Volacanic eruption; $3 D$ representation with Digital Elevation Model: DEM; Open data API

\section{INTRODUCTION}

There are many remote sensing portals in the world. Most of them are dedicated to scientific research based data driven portal sites. The most famous and useful site among them is Geoss portal which allows access to the data servers through the portal. On the other hand, most of space agencies create their own remote sensing satellite data servers. Meanwhile, Free Open Source Software: FOSS of data analysis software tools is also available through the different software providers. It seems that there is no portal site which allows remote sensing satellite data access, FOSS of software access, examples of data analysis and instructions of data analysis procedure with government providing open data in particular for practical use of the remote sensing satellite data dedicated to local governments. For instance, federal and state governments provide open data together with open data API. By using such government providing open data, practical use of remote sensing satellite data can be done easily.

There are many previously proposed methods for information and image retrievals in particular for remote sensing satellite data [1]-[20]. This paper is intended to provide the aforementioned purpose of remote sensing portal site for practical uses which is dedicated to local governments is created. Key components of the site are (1) links to data providers, (2) links to the data analysis software tools, (3) examples of actual uses of the satellite remote sensing data in particular for local governments. Users' demands for remote sensing satellite data are investigated for the local governments situated in Kyushu, Japan. According to the users' demands, the remote sensing portal site is created with the aforementioned key components. For the examples of remote sensing data applications, creation of land use maps, disaster mitigations, forest maps, vegetation index map for evaluation of vitality of agricultural fields and forests, etc. are taken into account. In particular for forest map creation, it is created with FOSS of classifiers together with open data API derived training samples applied to Landsat-8 OLI data. On the other hand, volcanic eruption is featured for disaster relief with 3D representation by using open data derived DEM data. In accordance with the users' evaluation reports, it is found that the proposed portal site is useful.

This paper is organized as (1) investigation of users' demands on practical uses of remote sensing satellite data in particular for the local governments which are situated in Kyushu, Japan, (2) design of the proposed remote sensing portal site, (3) examples of practical uses of remote sensing satellite data utilizing open data which are provided by the government, and (4) concluding remarks together with some discussions.

\section{Proposed Portal Site for Practical Uses of REMOTE SENSING SATELLITE DATA}

\section{A. Hearing of the Users' Demands on Practical Uses of Remote Sensing Satellite Data from the Local Governments in Kyushu, Japan}

Investigation is conducted for clarifying users' demands on practical uses of remote sensing satellite data from the local governments in Kyushu, Japan. The followings are users' demands,

(1)Agricultural and forestry applications

Rice crop quality map

High quality of tealeaves map

Total nitrogen content in agricultural fields

Agricultural productivity map

Forest inventory map

Forest type and age estimations

Bamboo forest map

(2)Water resources and quality monitoring 
Run-off water resource map

Water resource management

(3)Disaster

Disaster mitigation

Hazard map

Volcanic monitoring

Tsunami prediction

Illegal disposal findings

(4)Atmospheric environment

Air pollution map

Solar irradiance estimation

(5)Ocean monitoring

Ocean monitoring

Renewable resources monitoring

Nutrient rich water map

Red tide

River and coastal area monitoring and planning

The largest users' demands are agricultural and forest monitoring followed by disaster monitoring. The reason for this is the fact that the largest industry in Kyushu is agriculture and forest resources. Ocean monitoring and water resources as well as atmospheric environment are followed by. The Kyushu is surrounded by the ocean. Therefore, fishery is a major industry in Kyushu. In Kyushu, there are so many active volcanoes. It is so frequently that typhoon hit Kyushu. This is because the disaster related users' demands are dominated. Other than these, there is strong demand on solar energy monitoring for solar power plantation of electricity provides. Also, air pollution comes from the Asian continent. Therefore, air pollutions including PM2.5 is major concern for Kyushu.

\section{B. Design Concept}

There are four major key components for the proposed portal site. Those are as follows,

1) Links to the major remote sensing satellite data providers

2) Links to the major sites for data analysis software providers

3) Links to the major sites for open data which are applicable to remote sensing data analysis data.

4) Examples of practical uses of remote sensing satellite

Namely, the proposed portal site is intended to provide the aforementioned four major links and information, data providers, software providers, open data providers, and examples of practical uses of the remote sensing satellite data for local governments.

\section{The Links to the Remote Sensing Satellite Data Providers}

There are many remote sensing satellite data providers. Local governments need solar reflectance wavelength region of the surface reflectance channels of data with a high spatial resolution (higher than $30 \mathrm{~m}$ ) with free of charge (downloadable from their sites freely). Therefore, Landsat ETM+, TM, OLI, ASTER/VNIR, ASTER/SWIR are candidates. Such these users' requirements are matched to the following sites,
1) Unite State Geological Survey: USGS ${ }^{1}$

2) National Institute of Advanced Industrial Science and Technology: AIST ${ }^{2}$

3) Libra $^{3}$

4) Reverb $\mid \mathrm{ECHO}^{4}$

5) JAXA G-Portal ${ }^{5}$

Screen shot images of the data providers are shown in Fig.1. Fig.1 (a) shows USGS site followed by AIST of Landsat viewer in Fig.1 (b). In particular for AIST site, there is a comprehensive map utilizing retrieval site as shown in Fig.1 (c). Fig.1 (d) shows Libra site provided by Libra development seed organization. NASA/EOSDIS provides the Reverb | ECHO as shown in Fig.1 (e). Meanwhile, Fig.1 (f) shows JAXA G-Portal which allows remote sensing satellite data by application fields and by mission instruments.
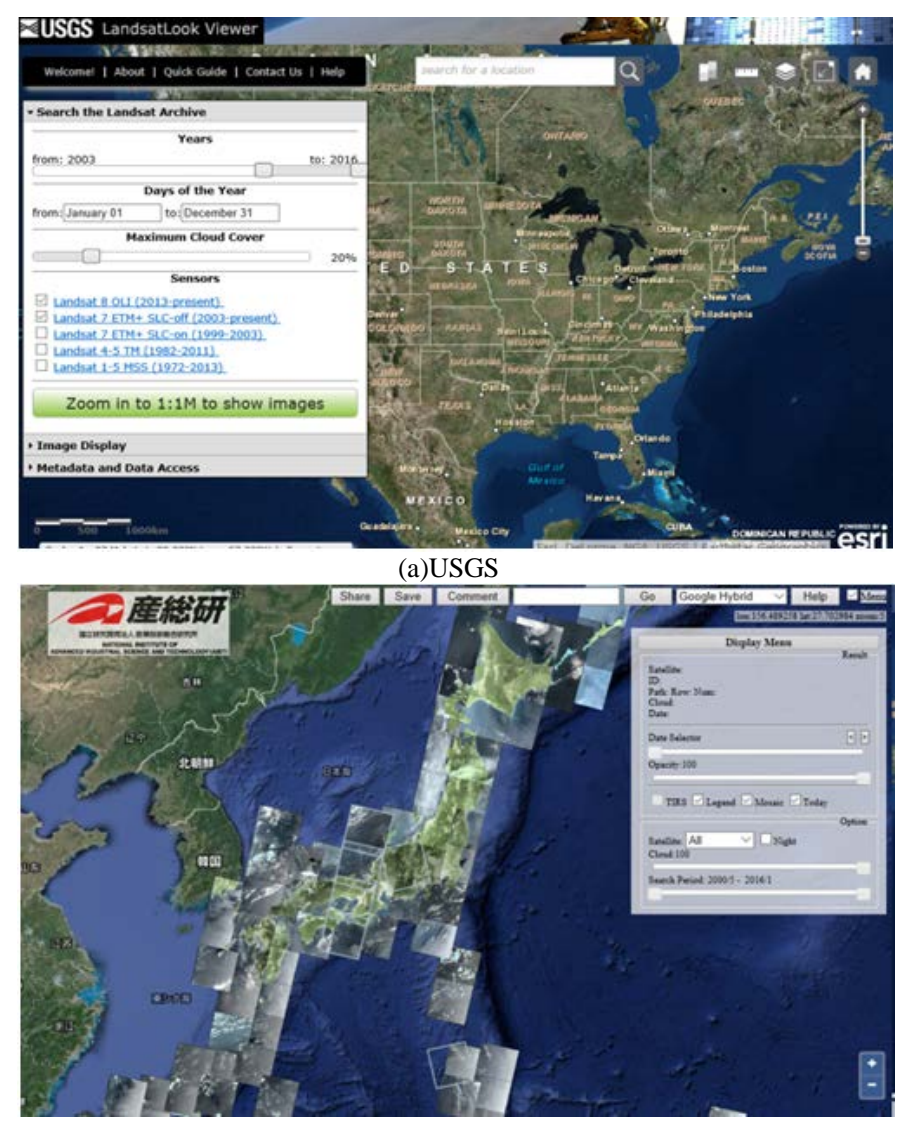

(b)AIST

\footnotetext{
${ }^{1}$ http://landsatlook.usgs.gov/

${ }^{2}$ http://landbrowser.geogrid.org/landbrowser/index.html

${ }^{3} \mathrm{http}: / /$ libra.developmentseed.org/

http://reverb.echo.nasa.gov/reverb/\#utf8=\%E2\%9C\%93\&spatial_map=satellit e\&spatial_type=rectangle

${ }^{5}$ https://www.gportal.jaxa.jp/gp/date-and-

area.html?F1108489815937N0QOGR=
} 


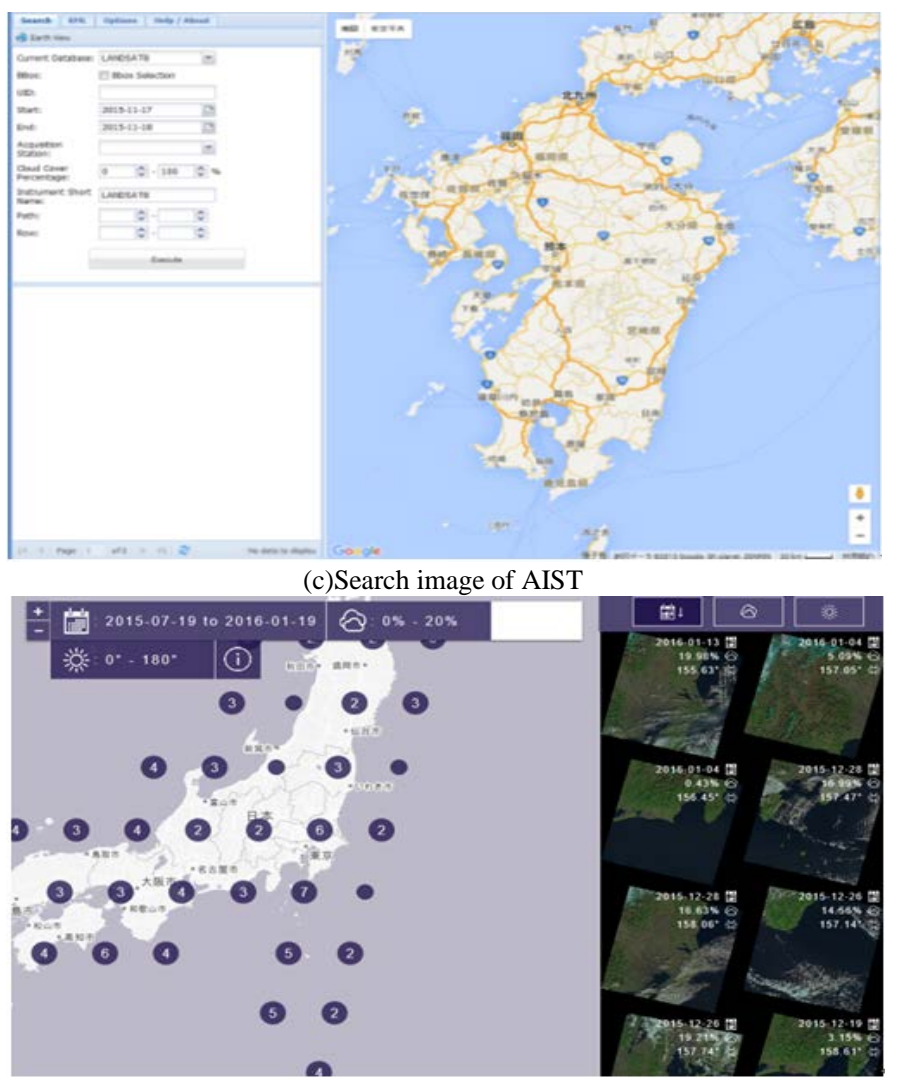

(d)Libra

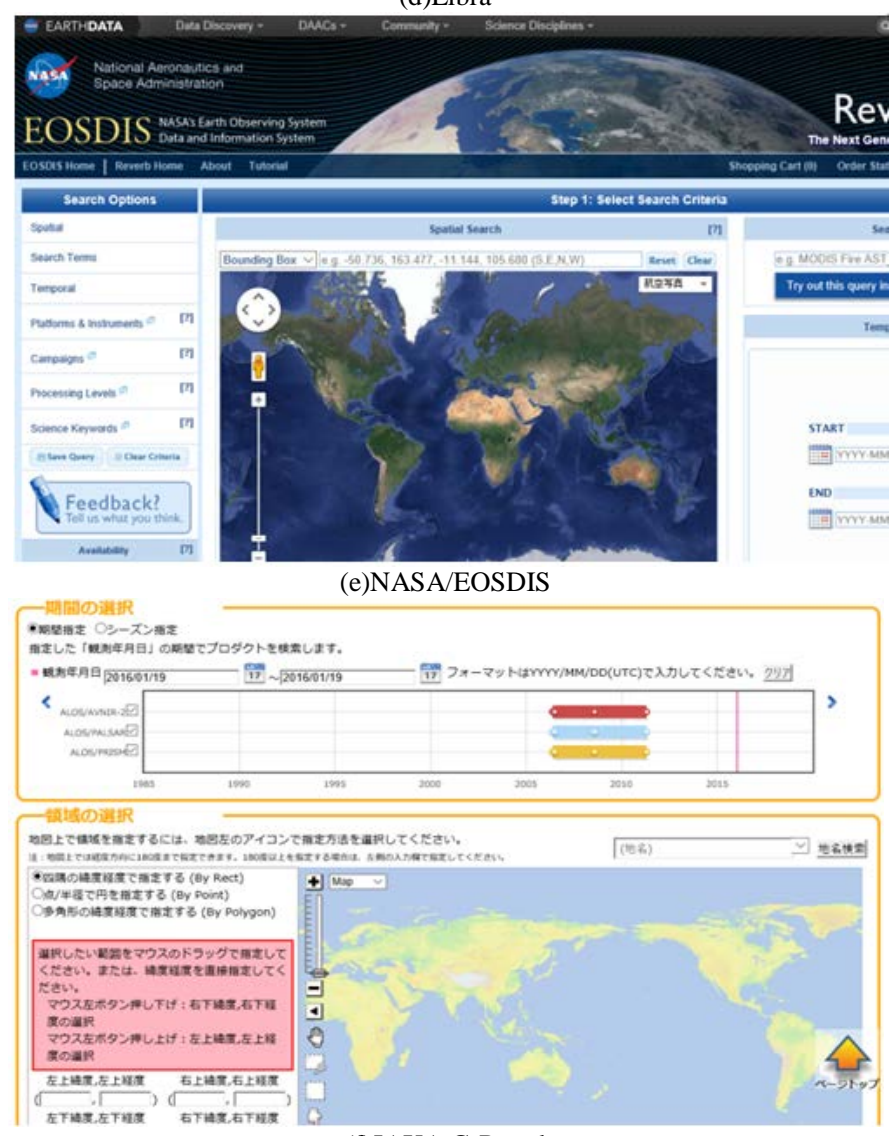

(f)JAXA G-Portal

Fig. 1. Examples of the remote sensing satellite data retrieval sites

\section{The Links to the Open Data Providers}

Open data $^{6}$ is available and is useful for remote sensing satellite data analysis. For instance, training samples for land uses of the open data is useful for land use map creations. Open data initiative of $\operatorname{Japan}^{7}$ is launched in 2012. The home page of the open data site in Japan is as shown in Fig.2 (a). Through the home page, the open data provided by ministries and local governments are accessible as shown in Fig.2 (b).
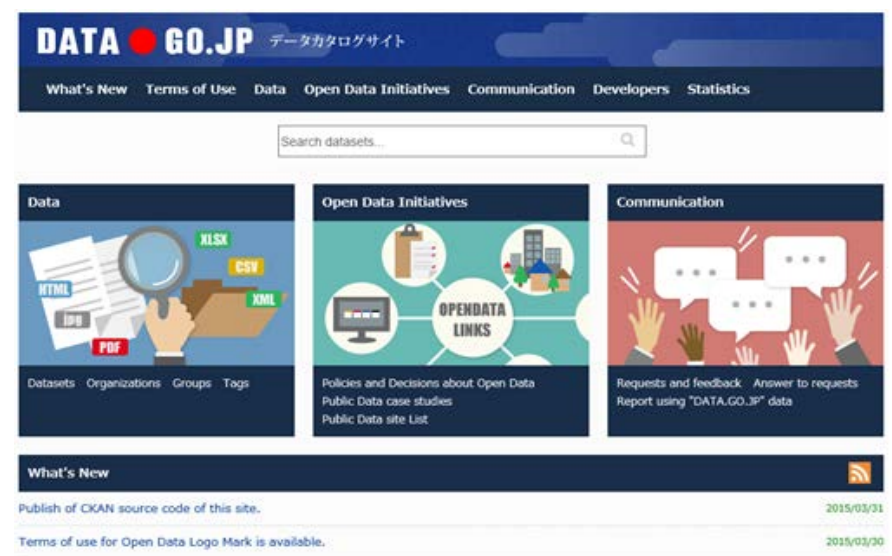

(a)Home page

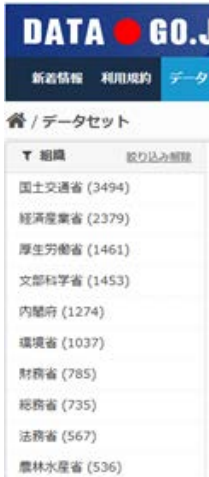

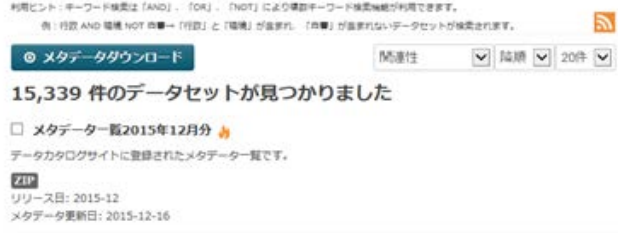

(b)List of the available open data

Fig. 2. Open data initiative in Japan (Home page and the list of available data of the open data)

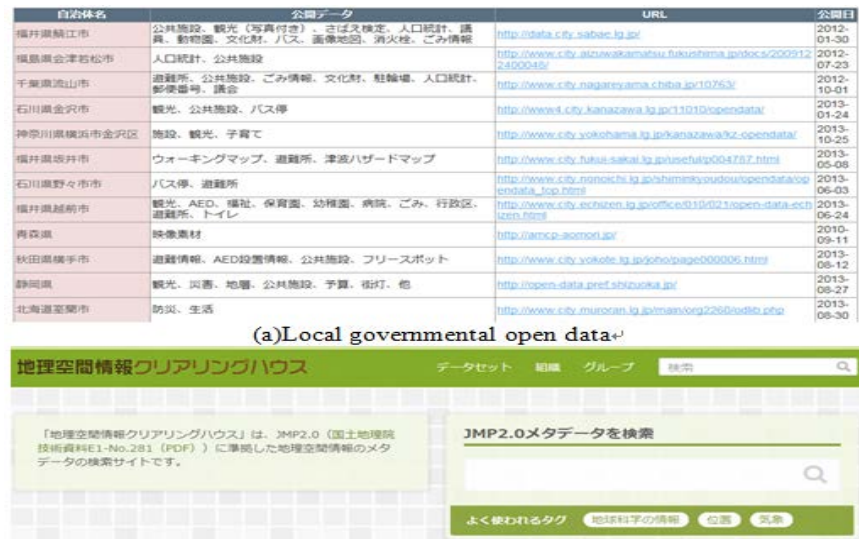

(b)Geographical spatial information of open data

Fig. 3. Screen shots of local governmental open data and geographical statial information

${ }^{6}$ https://en.wikipedia.org/wiki/Open_data

http://www.data.go.jp/?lang=english 
A portion of available open data provided by the local governments in Japan is shown in Fig.3 (a) while the home page of the clearing house of geographical spatial information is shown in Fig.3 (b). Links to the local government open data sites of URLs are available from the site of Fig.3 (a) while JMP2.0 based metadata search is available for the clearing house.

\section{E. The Links to the Software Providers}

Most of local governments prefer Free Open Source Software: FOSS of analysis software tools rather than commercially available software. MultiSpec ${ }^{8}$ is one of those of FOSS. Meanwhile, $\operatorname{RSP}^{9}$ is sophisticated image analysis software dedicated to the remote sensing satellite data analysis which is provided by the Aoyama construction company limited. On the other hand, QGIS ${ }^{10}$ is sophisticated software which is developed by QGIS development team. One of the specific features of QGIS is available programming languages, $\mathrm{C}++$, Python ${ }^{11}, \mathrm{Qt}^{12}$. Therefore, it is relatively easy to utilize the software with the uses' developed software. Furthermore, QGIS is cross platform FOSS which allows refers, edit, and analyze the imagery data on GIS (Geographical Information System).

Common functionalities of these software tools are as follows,

1) File manipulations including format conversion, image portion extraction, pan-sharpening, color composite, etc.

2) Geometric corrections including Affine transformation, pseudo Affine transformation, etc.

3) Filtering processing which includes mask processing, median filter, edge extraction, etc.

4) Image operation processing including add, subtract, multiply, division, NDVI calculation, etc.

5) Analysis including correlation analysis, principal component analysis, etc.

6) Color information manipulations which include enhancing, binarization, histogram manipulations, pseudo color representation, multi-level slicing, etc.

7) Image display which includes enlargement, shrinking, etc.

8) Image classification including maximum likelihood classification, clustering, etc.

9) Geographical analysis including Digital Elevation Model: DEM representation, DEM editing, slope elevation and azimuth angle calculation, etc.

\section{F. Examples of Practical Uses of Remote Sensing Satellite Data}

Major concerns of local governments have to be referred through the proposed portal site. In the site, (1) NDVI calculation for forest vitality monitoring, (2) forest inventory

\footnotetext{
${ }^{8}$ http://itcweb.cc.affrc.go.jp/affrit/sidab-info/satellite/multispec

${ }^{9}$ http://rs.aoyaman.com/soft/item.html

${ }^{10} \mathrm{http} / / /$ www.qgis.org/ja/site/forusers/download.html

${ }^{11}$ https://www.python.org/

${ }^{12}$ https://ja.wikipedia.org/wiki/Qt
}

map creation which includes forest type classification, (3) sediment disaster due to volcanic eruptions, etc. are referred.
1) NDVI calculation for forest vitality monitoring
NDVI is expressed as follows,

$$
\text { NDVI=(NIR-Red)/(NIR+Red) }
$$

where NIR, Red denote leaf surface reflectance at Near Infrared wavelength region (more than 700nm) and that at red color wavelength (around 600nm), respectively. NDVI represents vitality of the tree and or the forest. In Kyushu, most of prefectural local governments concern forest vitality. NDVI has positive correlation to total nitrogen content in the leaves and has negative correlation to fiber content in the leaves. Total nitrogen content is highly correlated to tree or forest vitality while fiber content is highly correlated to age of the leaves. Therefore, total vitality of tree or forest can be estimated with NDVI. By using the correlations, quality of agricultural products, in particular, tea trees vitality and quality of tealeaves can be estimated.

Fig.4 shows an example of the NDVI estimated with Terra/ASTER/VNIR data which are acquired in the winter seasons. In the winter season, tea trees are patients for the next coming sprinter season maintaining their vitality. In such season (approximately five months), a fine condition of remote sensing satellite data can be acquired.Fig.5 (a) to (e) shows NDVI images in 2011 to 2015 which are estimated with the VNIR image of Ureshino district, Saga, Kyushu, Japan in where many tea farm areas are situated. Thus quality of new fresh tealeaves can be estimated. These NDVI images can be created with image operations and manipulations using RSP, QGIS and the other remote sensing imagery data processing software.

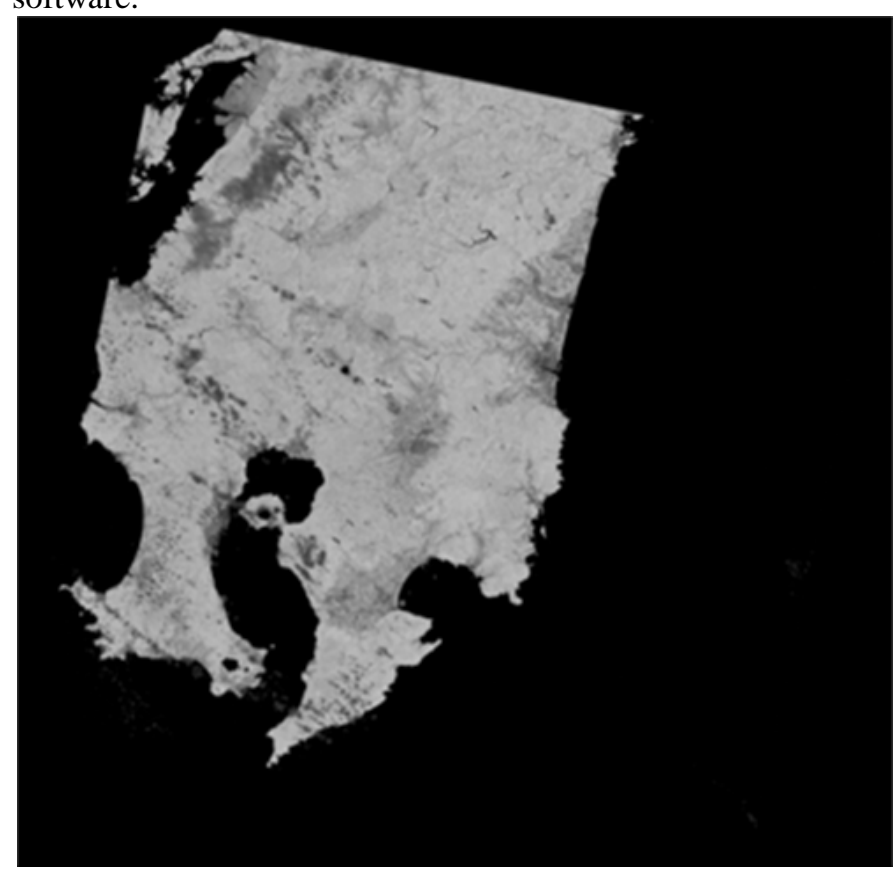

Fig. 4. Example of NDVI image of Southern Kyushu, Japan 


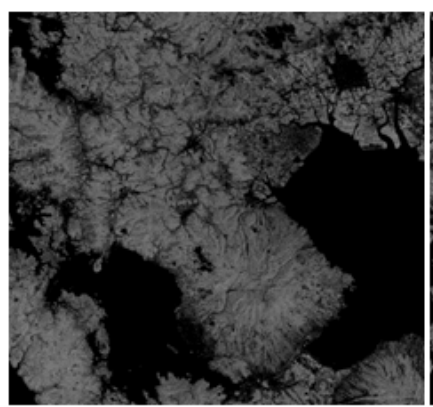

(a) 2011

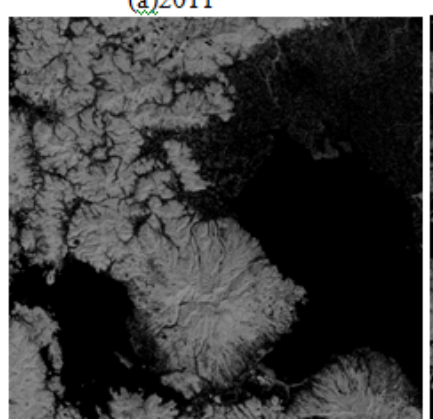

(c)2013

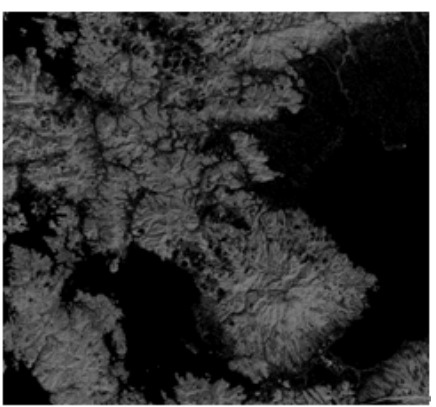

(b) 2012

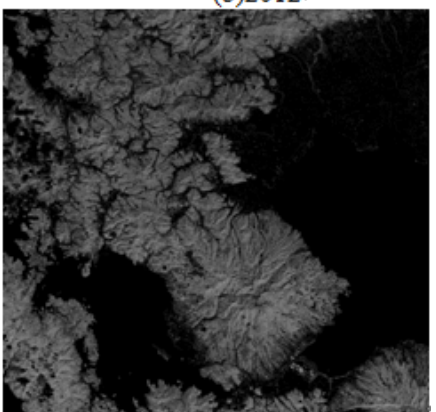

(d)2014

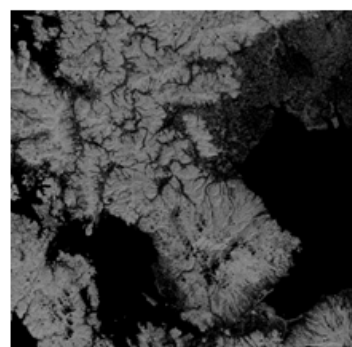

(e)2015

Fig. 5. NDVI images of Ureshino city Saga Japan in the winter seasons of 2011 to 2015

2) Forest inventory map creation which includes forest type classification

Landsat-8/OLI imagery data which is acquired on May 2 2015 can be retrieved and download through AIST site. One of the examples of false color representation of image is shown in Fig.6 (a). Meanwhile, classified image is easily created with RSP software (class\#1: Ocean, class\#2: River water, class\#3: vegetated areas, class\#4: Bare soil, class\#5: Urbanized areas) as shown in Fig.6 (b). It is possible to extract training samples for classification through referring Open Data of previously classified image with Open Data API.

Forest type classification is also available with previously created open data of forest map (Fig.7 (a)) for forest inventory provided by prefectural local government which is downloaded through Open Data portal with Open Data API. Example of the classified result is shown in Fig.7 (b) with the legends as shown in Fig.7 (c). By using DEM data provided by geological survey of Japan through Open Data portal, bird view image of classification result can be created easily as shown in Fig.7 (d). Therefore, classified results can be represented from different aspects with QGIS software.

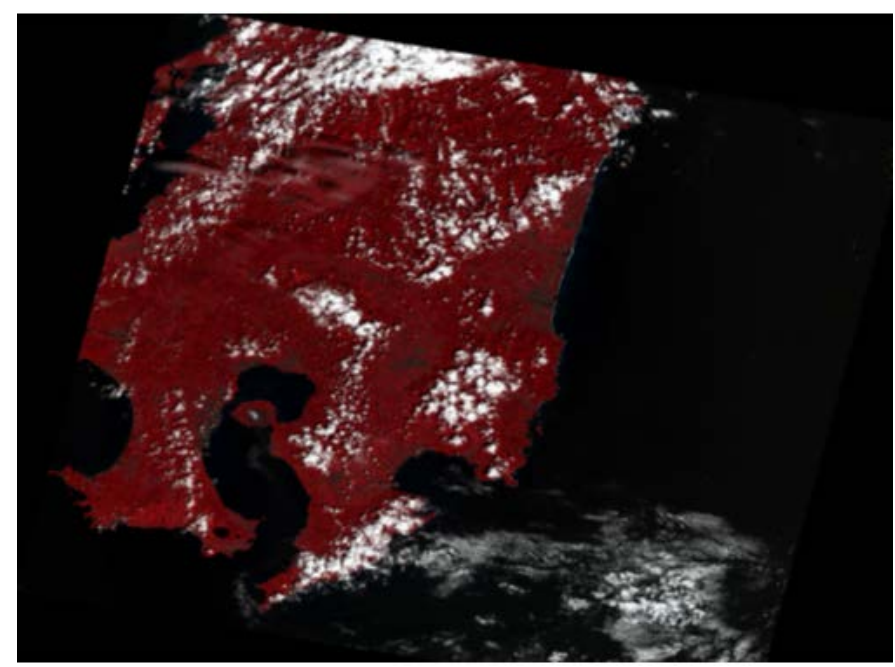

(a)False color

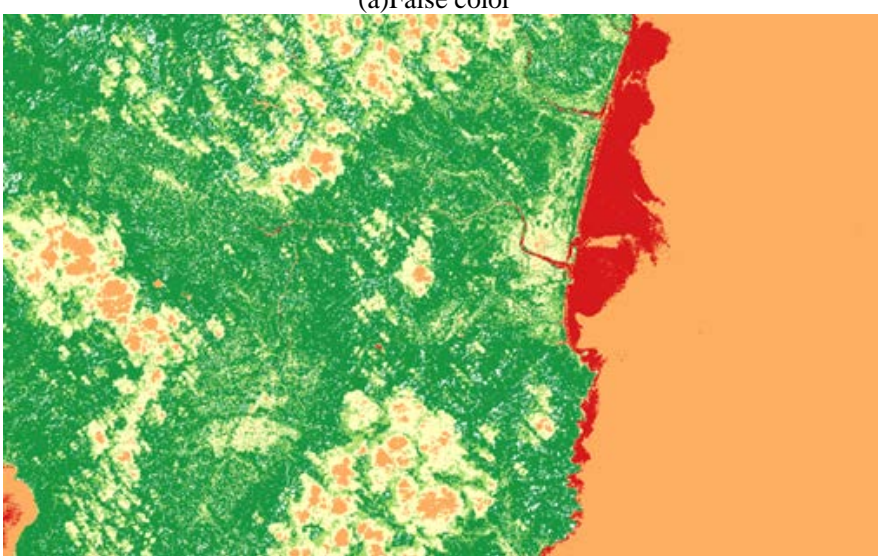

(b)Classified image

Fig. 6. Example of downloaded image of Landsat-8/OLI and classified image

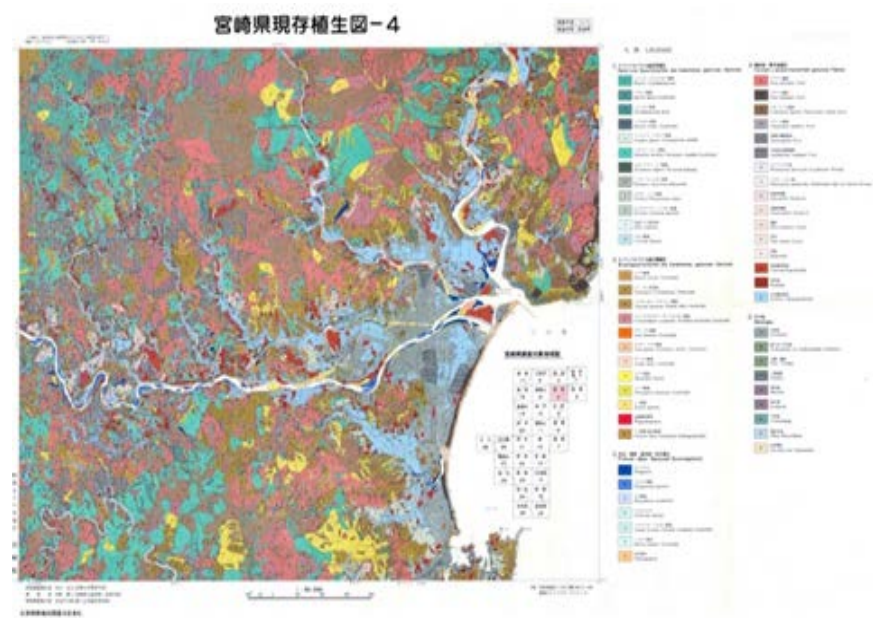

(a)Forest Map 


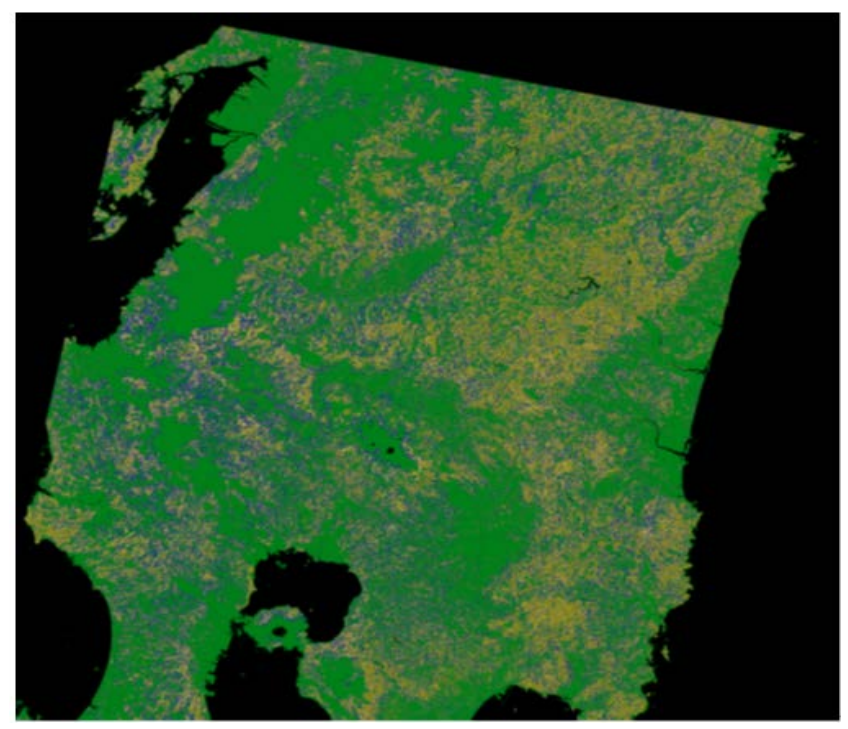

(b)Classified image

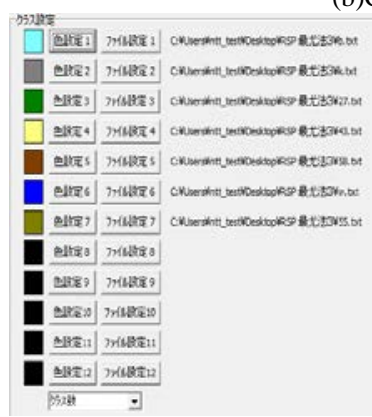

(c)Legend of the classification

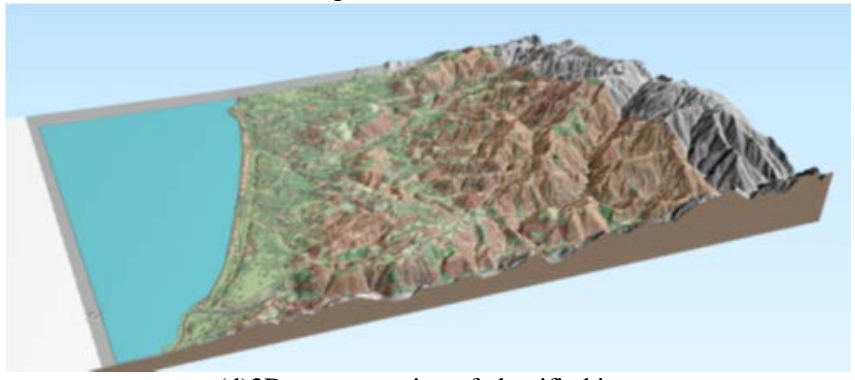

(d)3D representation of classified image

Fig. 7. Forest inventory application of remote sensing satellite data

3) Sediment disaster due to volcanic eruptions

Land slide (sediment disaster) due to volcanic eruption can be detected by extracting land cover changes from vegetated areas to non-vegetated areas (bare soil) form the two different remote sensing satellite imagery data which are acquired before and after the eruption. Active volcano of Sakurajima Mountain, Kagoshima, Kyushu, Japan is erupted during August 9 and September 10 2015. On August 15, caution level is raised from 3 to 4 and then that is dropped from 4 to 3 on September 1. By comparing two Landsat-8/OLI images which are acquired on August 9 and September 10, land slide areas are detected. Using QGIS, land slide areas which are colored in red can be detected and represented as shown in Fig.8 (a) to (c) from the different aspects. Through comparison between analyzed land slide areas and local government provided land slide data (truth data), it is found that they show a good coincident.

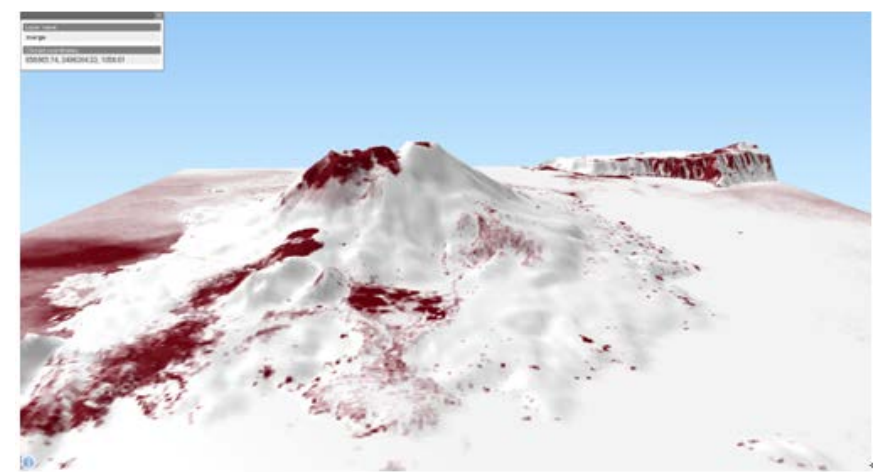

(a)From A aspect

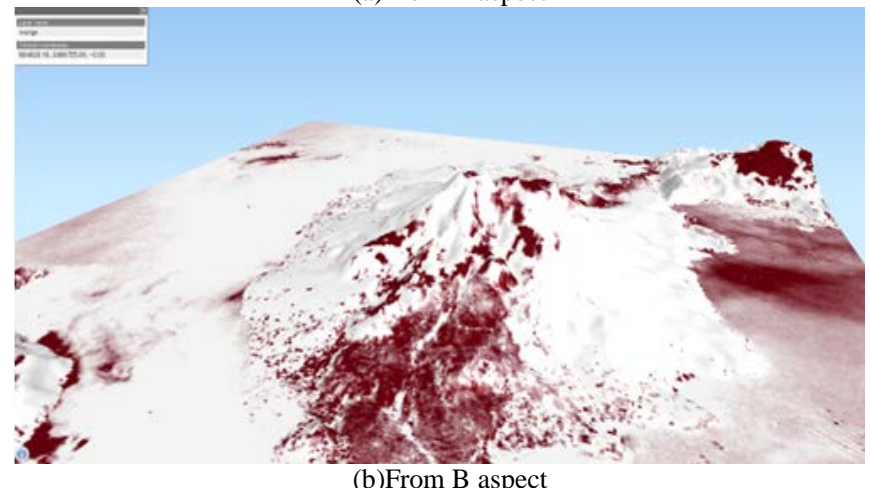

(b)From B aspect

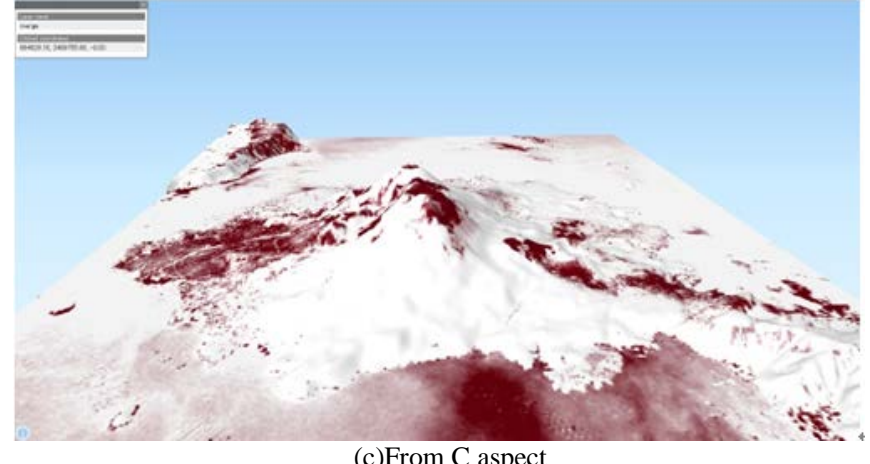

(c)From C aspect

Fig. 8. Land slide and/or sediment disaster areas (red color portion) of Sakurajima Mountain in August 2015

\section{CONCLUSION}

Remote sensing portal site for practical uses which is dedicated to local governments is created. Key components of the site are (1) links to data providers, (2) links to the data analysis software tools, (3) examples of actual uses of the satellite remote sensing data in particular for local governments. Users' demands for remote sensing satellite data are investigated for the local governments situated in Kyushu, Japan. According to the users' demands, the remote sensing portal site is created with the aforementioned key components. For the examples of remote sensing data applications, creation of land use maps, disaster mitigations, forest maps, vegetation index map for evaluation of vitality of agricultural fields and forests, etc. are taken into account. In particular for forest map creation, it is created with free open source software: FOSS of classifiers together with open data API derived training samples applied to Landsat-8 OLI data. On the other hand, volcanic eruption is featured for disaster relief with 3D representation by using open data derived DEM data. In 
accordance with the users' evaluation reports, it is found that the proposed portal site is useful.

Further investigation is required for increasing application examples in particular for matching to the prefectural local government need.

\section{ACKNOWLEDGMENT}

The author would like to thank all the participants to this project (Kyushu Aeronautical and Space Development Promotion Committee Members) and Mr.Masanori Sakashita of Graduate School of Science and Engineering of Saga University in Japan for his effort to conduct users' demand investigations and simulation studies.

\section{REFERENCES}

[1] Shin-ichi Sobue, Kohei Arai, Osamu Ochiai, Inter-Operable Protocol for Earth Observation Satellite Data Retrievals, Journal of Information Processing Society of Japan, Vol.39, No.3, 222-228, Mar.1998.

[2] Kohei Arai, Manabu Arakawa, Hirofumi Etoh, Fuzzy Search of Earth Observation Data Retrievals Using Physical and Spatial features Based on Fuzzy Theory, Journal of Japan Society of Photogrammetry and Remote Sensing,, Vol.38, No.4, pp.17-25, Aug.1999.

[3] Hirofumi Etoh, Takahiro Yamamoto, Kohei Arai, Indexing Method for Image Database Retrievals by Means of Spatial Features, Journal of Japan Society of Photogrammetry and Remote Sensing,, Vol.39, No.3, pp.14-20,(2000).

[4] Kohei Arai, Bu Kenkyo, Image portion retrievals in large scale imagery data by using online clustering taking into account pusuite algorithm based Reinforcement learning and competitive learning, Journal of Image Electronics Society of Japan, 39, 3, 301-309, 2010

[5] Kohei Arai, Visualization of 3D object shape complexity with wavelet descriptor and its application to image retrievals, Journal of Visualization, DOI:10.1007/s, 12650-011-0118-6, 2011.

[6] K.Arai, C.Rahmad, Wavelet based image retrieval method, International Journal of Advanced Computer Science and Applications, 3, 4, 6-11, 2012.

[7] K.Arai, DP matching based image retrieval method with wavelet Multi Resolution Analysis: MRA which is robust against magnification of image size, International Journal of Research and Review on Computer Science, 3, 4, 1738-1743, 2012.

[8] K.Arai, Free Open Source Software: FOSS based GIS for spatial retrievals of appropriate locations for ocean energy utilizing electric power generation plants, International Journal of Advanced Computer Science and Applications, 3, 9, 95-99, 2012.

[9] K.Arai, Visualization of link structure and URL retrievals utilization of interval structure of URLs based on brunch and bound algorithms, International Journal of Advanced Research in Artificial Intelligence, 1, 8, 12-16, 2012.

[10] Kohei Arai, Method for image portion retrieval and display for comparatively large scale of imagery data onto relatively small size of screen which is suitable to block coding of image data compression, International Journal of Advanced Computer Science and Applications, 4, 2, 218-222, 2013.
[11] Kohei Arai, Cahya Rahmad, Content based image retrieval by using multi-layer centroid contour distance, International Journal of Advanced Research in Artificial Intelligence, 2, 3, 16-20, 2013.

[12] Kohei Arai, Remote sensing satellite image database system allowing image portion retrievals utilizing principal component which consists spectral and spatial features extracted from imagery data, International Journal of Advanced Research in Artificial Intelligence, 2, 5, 32038, 2013.

[13] Kohei Arai, Image retrieval and classification method based on Euclidian distance between normalized features including wavelet descriptor, International Journal of Advanced Research in Artificial Intelligence, 2, 10, 19-25, 2013.

[14] Kohei Arai, Numerical representation of web sites of remote sensing satellite data providers and its application to knowledge based information retrievals with natural language, International Journal of Advanced Research in Artificial Intelligence, 2, 10, 26-31, 2013.

[15] K.Arai, Indra Nugraha Abudullar, Hiiroshi Okumura, Image retrieval based on color, shape and texture for ornamental leaf with medicinal functionality, International journal of Image, Graphics and Signal Processing, Vol.6, No.7, June 2014

[16] Cahya Rahmad, K.Arai, Comparison contour extraction based on layered structure and Fourier descriptor on image retrieval, International Journal of Advanced Research on Artificial Intelligence, 4, 12, 71-74, 2015.

[17] S.Sobue and K.Arai, Metadata Definition and Retrieval of Earth Observation Satellite Data, Proceedings of the IEEE Meatadata Conference, (1997)

[18] Kohei Arai, Open GIS with spatial and temporal retrievals as well as assimilation functionality, Proceedings of the Asia Pacific Advanced Network Natural Resource Workshop, Utilization of Earthy Observation Satellite-Digital Asia Special Session 1,p8, 2003.

[19] Kohei Arai, Yuji Yamada, Image retrieval method based on hue information and wavelet description based shape information as well as texture information of the objects extracted with dyadic wavelet transformation, Proceedings of the 11th Asian Symposium on Visualization, ASV-11-08-10, 1-8, 2011.

[20] K.Arai, C.Rahmad, Wavelet based image retrievals, Proceedings of the 260th conference in Saga of Image and Electronics Engineering Society of Japan, 243-247, 2012.

\section{AUTHORS PROFILE}

Kohei Aarai He received BS, MS and PhD degrees in 1972, 1974 and 1982, respectively. He was with The Institute for Industrial Science and Technology of the University of Tokyo from April 1974 to December 1978 and also was with National Space Development Agency of Japan from January, 1979 to March, 1990. During from 1985 to 1987, he was with Canada Centre for Remote Sensing as a Post Doctoral Fellow of National Science and Engineering Research Council of Canada. He moved to Saga University as a Professor in Department of Information Science on April 1990. He was a councilor for the Aeronautics and Space related to the Technology Committee of the Ministry of Science and Technology during from 1998 to 2000. He was a councilor of Saga University for 2002 and 2003. He also was an executive councilor for the Remote Sensing Society of Japan for 2003 to 2005. He is an Adjunct Professor of University of Arizona, USA since 1998. He also is Vice Chairman of the Commission-A of ICSU/COSPAR since 2008. He wrote 33 books and published 510 journal papers. He is Editor-in-Chief of International Journal of Advanced Computer Science and Applications as well as I ternational Journal of Intelligent Systsems and Applications. http://teagis.ip.is.saga-u.ac.jp/ 